\title{
Development of a Standardized Set of Patient-centered Outcomes for Advanced Prostate Cancer: An International Effort for a Unified Approach
}

\author{
Alicia K. Morgans ${ }^{a, \dagger, *}$, Annelotte C.M. van Bommel ${ }^{b, c, \dagger}$, Caleb Stowell ${ }^{b}$, Janet L. Abrahm ${ }^{d}$, \\ Ethan Basch $^{e}$, Justin E. Bekelman ${ }^{f}$, Donna L. Berry ${ }^{d}$, Alberto Bossi ${ }^{g}$, Ian D. Davis ${ }^{h}$, \\ Theo M. de Reijke ${ }^{i}$, Louis J. Denis ${ }^{j, k}$, Sue M. Evans ${ }^{l}$, Neil E. Fleshner ${ }^{m}$, Daniel J. George ${ }^{n}$, \\ Jim Kiefert ${ }^{o}$, Daniel W. Lin ${ }^{p}$, Andrew G. Matthew ${ }^{m}$, Ray McDermott ${ }^{q}$, Heather Payne ${ }^{r}$, \\ Ian A.G. Roos ${ }^{s}$, Deborah Schrag ${ }^{d}$, Thomas Steuber ${ }^{t}$, Bertrand Tombal ${ }^{u}$, Jean-Paul van Basten ${ }^{v}$, \\ Jacobus J.M. van der Hoeven ${ }^{w}$, David F. Penson ${ }^{a, x}$, \\ on behalf of the Advanced Prostate Cancer Working Group of the International Consortium for \\ Health Outcomes Measurement
}

\begin{abstract}
${ }^{a}$ Vanderbilt University Medical Center, Nashville, TN, USA; ${ }^{\mathrm{b}}$ International Consortium for Health Outcomes Measurement, Cambridge, MA, USA; ${ }^{\mathrm{c}}$ Dutch Institute for Clinical Auditing, Leiden, The Netherlands; ${ }^{\mathrm{d}}$ Dana-Farber Cancer Institute, Boston, MA, USA; ${ }^{\mathrm{e}}$ University of North Carolina at Chapel Hill, Chapel Hill, NC, USA; ${ }^{\mathrm{f}}$ University of Pennsylvania, PA, USA; ${ }^{\mathrm{g}}$ Gustave Roussy Cancer Institute, Villejuif, France; ${ }^{\mathrm{h}}$ Monash University Eastern Health Clinical School, Melbourne, Australia; ${ }^{\mathrm{i}}$ Academic Medical Center Amsterdam, Amsterdam, The Netherlands; ${ }^{\mathrm{j}}$ Oncology Centre Antwerp, Antwerp, Belgium; ${ }^{\mathrm{k}}$ US TOO Belgium, Antwerp, Belgium; ${ }^{1}$ Monash University, Melbourne, Australia; ${ }^{\mathrm{m}}$ University of Toronto, Toronto, Canada; ${ }^{\mathrm{n}}$ Duke University Medical Center, Durham, NC, USA; ${ }^{\circ}$ US TOO International, Des Plaines, IL, USA; ${ }^{\mathrm{p}}$ University of Washington, Seattle, WA, USA; ${ }^{\mathrm{q}}$ St. Vincent's University Hospital, Dublin, Ireland; ${ }^{\mathrm{r}}$ University

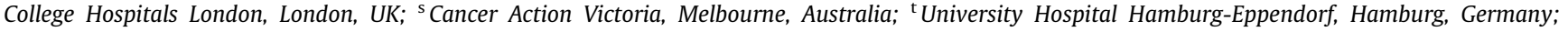
${ }^{\mathrm{u}}$ Cliniques Universitaires Saint Luc, Université Catholique de Louvain, Brussels, Belgium; ${ }^{\mathrm{v}}$ Canisius Wilhelmina Hospital, Nijmegen, The Netherlands; ${ }^{\mathrm{w}}$ Leiden University Medical Center, Leiden, The Netherlands; ${ }^{x}$ VA Tennessee Valley Geriatric Research, Education, and Clinical Center (GRECC), Nashville, TN, USA
\end{abstract}

Article info

Article history:

Accepted June 9, 2015

Associate Editor:

James Catto

Keywords:

Outcome assessment (health

care)

Patient-centered care

Prostate cancer

Quality indicators

\begin{abstract}
Background: There are no universally monitored outcomes relevant to men with advanced prostate cancer, making it challenging to compare health outcomes between populations. Objective: We sought to develop a standard set of outcomes relevant to men with advanced prostate cancer to follow during routine clinical care.

Design, setting, and participants: The International Consortium for Health Outcomes Measurement assembled a multidisciplinary working group to develop the set. Outcome measurements and statistical analysis: We used a modified Delphi method to achieve consensus regarding the outcomes, measures, and case mix factors included. Results and limitations: The 25 members of the multidisciplinary international working group represented academic and nonacademic centers, registries, and patients. Recognizing the heterogeneity of men with advanced prostate cancer, the group defined the scope as men with all stages of incurable prostate cancer (metastatic and biochemical recurrence ineligible for further curative therapy). We defined outcomes important to all men, such as overall survival, and measures specific to subgroups, such as time to metastasis. Measures gathered from clinical data include measures of disease control.

\footnotetext{
$\dagger$ These authors contributed equally to this work.

* Corresponding author. Division of Hematology/Oncology, Vanderbilt University Medical Center, 2220 Pierce Avenue, 777 Preston Research Building, Nashville, TN 37232, USA. Tel. +1 615 3224967; Fax: +1 6153437602 .
}

E-mail address: alicia.morgans@vanderbilt.edu (A.K. Morgans).
\end{abstract}

http://dx.doi.org/10.1016/j.eururo.2015.06.007

0302-2838/C 2015 The Authors. Published by Elsevier B.V. on behalf of European Association of Urology. This is an open access article under the CC BY-NC-ND license (http://creativecommons.org/licenses/by-nc-nd/4.0/). 
Health care

Palliative care
We also identified patient-reported outcome measures (PROMs), such as degree of urinary, bowel, and erectile dysfunction, mood symptoms, and pain control.

Conclusions: The international multidisciplinary group identified clinical data and PROMs that serve as a basis for international health outcome comparisons and quality-of-care assessments. The set will be revised annually.

Patient summary: Our international group has recommended a standardized set of patient-centered outcomes to be followed during routine care for all men with advanced prostate cancer.

(C) 2015 The Authors. Published by Elsevier B.V. on behalf of European Association of Urology. This is an open access article under the CC BY-NC-ND license (http:// creativecommons.org/licenses/by-nc-nd/4.0/).

\section{Introduction}

Prostate cancer is the most common noncutaneous malignancy among men and causes the death of hundreds of thousands of men each year worldwide [1]. The disease is heterogeneous, and treatment varies at each stage of disease. Although therapeutic guidelines have been developed by various organizations, significant variation in the care actually delivered in practice remains [2-4]. Evidence suggests that standardization of clinical practice may reduce unnecessary costs and improve quality of care, resulting in improved health care value [5].

In the case of advanced prostate cancer, value must be defined as it pertains to the consumer of care: the patient [6]. For prostate cancer, this encompasses not only survival but also a range of concerns regarding quality of life (QOL) and complications that are too often unmeasured. Outside of clinical trials and some registries and cohort studies, few institutions collect outcomes beyond mortality. The lack of meaningful measures for routine clinical practice makes direct comparisons of health outcomes across patient populations and between institutions challenging.

The International Consortium for Health Outcomes Measurement (ICHOM) has developed a recommended set of outcomes to be measured in a standardized way for localized prostate cancer, and this set is currently being monitored by a range of registries and provider organizations worldwide [7]. However, no such recommendation exists for advanced prostate cancer. To address this, we convened an international, multidisciplinary working group to develop a single standardized set of outcome measures pertinent to men with advanced prostate cancer for monitoring during routine clinical practice and to allow meaningful, systematic comparison of outcomes and quality of care across health systems.

\section{Materials and methods}

An advanced prostate cancer working group was assembled by ICHOM, a nonprofit organization that has developed standardized sets of pertinent outcomes for multiple medical conditions. ICHOM is supported by an array of organizations, including patient advocacy groups, specialty societies, hospitals and health systems, governments, and private payers (Supplementary material, Appendix 1). The diverse team of 25 experts includes patient representatives, epidemiologists, palliative care specialists, nurse oncologists, medical oncologists, urologists, and radiation oncologists from Europe, Australia, Canada and the USA. A smaller project team (A.V.B., A.K.M., C.S., and D.P.) guided the efforts of the larger group.
The working group convened via six teleconferences between June and December 2014, and proceeded through a structured process similar to that described for the localized prostate cancer set and elsewhere [7-10]. The project team performed a structured Medline (1990-2014) literature review and prepared a proposal describing the findings appropriate for discussion before each teleconference. The calls focused on the following: (1) scope and outcome domains; (2) outcome definitions and measures, including clinical data and patient-reported outcome measures (PROMs); (3) case mix factors; and (4) case mix measures. The Medline review retrieved randomized controlled trials and cohort studies including men with advanced prostate cancer to identify clinical outcomes and relevant measures of health-related QOL (HR-QOL) (Supplementary material, Appendices 2-4). To assure inclusion of all relevant studies, we also reviewed studies referenced in identified articles, and asked working group experts to name other sources that had not been identified. After each teleconference, we circulated a survey and each member voted anonymously regarding each topic. A modified Delphi method requiring consensus by two-thirds or more was required for inclusion of all proposed outcomes, case mix factors, and measures (Supplementary material, Appendix 5). Members of ICHOM maintained the data and conducted the surveys, but neither ICHOM nor its funders influenced voting or manuscript preparation.

\section{Results}

\subsection{Condition and treatment scope}

This set was designed to cover a heterogeneous group of men with prostate cancer who lack curative treatment options. This includes men with M1 disease as defined by American Joint Committee on Cancer staging, and men with biochemical recurrence ineligible for further curative therapy (Table 1) [11]. The working group acknowledged that the population to which this set applies is heterogeneous, but defined the scope to include patients who may have similar palliative goals of care. The set covers all forms of systemic treatment for prostate cancer, including antiresorptive treatment for prevention of symptomatic skeletal events (SSEs).

\subsection{Outcome domains}

After review of the literature and discussion, a list of 22 outcome domains was identified for discussion and voting by the working group. Pain, overall survival, cause-specific survival, and treatment complications were felt to be most important to patients, with each receiving 95\% support for inclusion. Additional prioritized domains included are noted in Table 2 and discussed below. Domains reviewed in the literature but not receiving sufficient support for 
Table 1 - Scope of the International Consortium for Health Outcomes Measurement advanced prostate cancer standard set

\begin{tabular}{|c|c|}
\hline Men with M1 disease & Defined by American Joint Committee on Cancer \\
\hline $\begin{array}{l}\text { Men with biochemical } \\
\text { recurrence who failed } \\
\text { or are ineligible for } \\
\text { salvage therapy }\end{array}$ & $\begin{array}{l}\text { Defined as rising PSA after primary therapy } \\
\text { - Treated with primary RP: PSA } \geq 0.2 \mathrm{ng} / \mathrm{ml} \text { followed by a second PSA } \geq 0.2 \mathrm{ng} / \mathrm{ml}{ }^{\text {a }} \\
\text { - Treated with primary EBRT: rise in PSA of } 2 \mathrm{ng} / \mathrm{ml} \text { over the nadir PSA; in practice, } \\
\text { this value is commonly confirmed by a second measurement }\end{array}$ \\
\hline $\begin{array}{l}\text { PSA = prostate-specific a } \\
\text { a Based on the Americal } \\
\text { b Based on recommenda }\end{array}$ & $\begin{array}{l}\text { ernal beam radiation therapy. } \\
\text { d Prostate Cancer Update [12]. } \\
\text { Conference [13]. }\end{array}$ \\
\hline
\end{tabular}

Table 2 - Summary of case mix variables for the International Consortium for Health Outcomes Measurement advanced prostate cancer standard set

\begin{tabular}{|c|c|c|c|c|c|}
\hline Category & Population & Measure & Supporting information & Timing & Data source $^{a}$ \\
\hline \multirow[t]{8}{*}{ Treatment approach } & All patients & \multicolumn{2}{|l|}{ ADT } & $\begin{array}{l}\text { Update at least } \\
\text { annually }\end{array}$ & Clinical \\
\hline & All patients & \multicolumn{2}{|l|}{$\begin{array}{l}\text { Hormonal therapy other } \\
\text { than ADT }\end{array}$} & $\begin{array}{l}\text { Update at least } \\
\text { annually }\end{array}$ & Clinical \\
\hline & All patients & \multicolumn{2}{|l|}{ Chemotherapy } & $\begin{array}{l}\text { Update at least } \\
\text { annually }\end{array}$ & Clinical \\
\hline & All patients & \multicolumn{2}{|l|}{ Immunotherapy } & $\begin{array}{l}\text { Update at least } \\
\text { annually }\end{array}$ & Clinical \\
\hline & All patients & \multicolumn{2}{|l|}{ Radiopharmaceuticals } & $\begin{array}{l}\text { Update at least } \\
\text { annually }\end{array}$ & Clinical \\
\hline & All patients & \multicolumn{2}{|l|}{ Radiation } & $\begin{array}{l}\text { Update at least } \\
\text { annually }\end{array}$ & Clinical \\
\hline & All patients & \multicolumn{2}{|l|}{ Bisphosphonates or denosumab } & $\begin{array}{l}\text { Update at least } \\
\text { annually }\end{array}$ & Clinical \\
\hline & All patients & \multicolumn{2}{|l|}{$\begin{array}{l}\text { Interventions for LP } \\
\text { complications }\end{array}$} & $\begin{array}{l}\text { Update at least } \\
\text { annually }\end{array}$ & Clinical \\
\hline \multicolumn{6}{|l|}{ Case mix variables } \\
\hline \multirow{6}{*}{$\begin{array}{l}\text { Demographic } \\
\text { factors }\end{array}$} & All patients & Age & Date of birth & Baseline & Clinical or PR \\
\hline & All patients & Body mass index & Height and weight & Baseline & Clinical or PR \\
\hline & All patients & Ethnicity & Determined by country & Baseline & PR \\
\hline & All patients & Educational level & Level of schooling completed ${ }^{\mathrm{b}}$ & Baseline & PR \\
\hline & All patients & Marital status & Relationship status & Baseline & PR \\
\hline & All patients & Living status & Living arrangements & Baseline & PR \\
\hline \multirow{6}{*}{$\begin{array}{l}\text { Baseline clinical } \\
\text { factors }\end{array}$} & All patients & Performance status & ECOG/WHO scale for performance status & Baseline & Clinical \\
\hline & All patients & Hb level at APC diagnosis & $\mathrm{Hb}$ level at time of APC diagnosis & Baseline & Clinical \\
\hline & All patients & Comorbidities & Modified SCQ ${ }^{c}$ & Baseline & PR \\
\hline & All patients & Pain score & Pain on scale of $0-10$ & Baseline & PR \\
\hline & All patients & Pain medication use & Use of OTC or strong pain medicine & Baseline & PR \\
\hline & All patients & Patient family history of PCa & First-degree relative with PCa diagnosis & Baseline & PR \\
\hline \multirow{4}{*}{$\begin{array}{l}\text { Baseline tumor } \\
\text { factors }\end{array}$} & All patients & PSA level at APC diagnosis & PSA value at time of APC diagnosis & Baseline & Clinical \\
\hline & All patients & Pathologic/clinical stage & Pathologic or clinical stage (AJCC [11]) & Baseline & Clinical \\
\hline & All patients & Gleason score & Gleason score at time of initial diagnosis & Baseline & Clinical \\
\hline & All patients & Metastatic disease & Radiographic or pathologic metastatic disease & Baseline & Clinical \\
\hline \multirow[t]{5}{*}{ Treatment factors } & All patients & Prior radical prostatectomy & Prior prostatectomy & Baseline & Clinical \\
\hline & All patients & Receipt of radiation therapy & Prior radiation to prostate & Baseline & Clinical \\
\hline & All patients & Receipt of ADT & Prior ADT & Baseline & Clinical \\
\hline & All patients & $\begin{array}{l}\text { Receipt of prior systemic } \\
\text { treatments }\end{array}$ & Prior systemic treatments other than ADT & Baseline & Clinical \\
\hline & All patients & $\begin{array}{l}\text { Receipt of bisphosphonates } \\
\text { or denosumab }\end{array}$ & Prior antiresorptive medication & Baseline & Clinical \\
\hline \multicolumn{6}{|c|}{$\begin{array}{l}\text { ADT = androgen deprivation therapy; } \mathrm{LP}=\text { local progression; } \mathrm{PR}=\text { patient-reported; ECOG = Eastern Cooperative Oncology Group; WHO = World Health } \\
\text { Organization; } \mathrm{Hb}=\text { hemoglobin; } \mathrm{APC}=\text { advanced prostate cancer; } \mathrm{SCQ}=\text { self-administered comorbidity questionnaire; PCa prostate cancer; AJCC = American } \\
\text { Joint Committee on Cancer; } \mathrm{PSA}=\text { prostate-specific antigen. } \\
\text { a The data source reflects the way case mix variables and outcomes are collected. Clinical data include data abstraction and physician reports. PR data include } \\
\mathrm{PR} \text { outcome measures and other relevant PR questions. } \\
\text { b Level of schooling defined in each country according to the International Standard Classification of Education. } \\
\text { ' Have you ever been told by a doctor that you have any of the following? I have no other disease, heart disease (eg, angina, heart attack, or heart failure), high } \\
\text { blood pressure, leg pain when walking due to poor circulation, lung disease (eg, asthma, chronic bronchitis, or emphysema), diabetes, kidney disease, liver } \\
\text { disease, problems caused by stroke, disease of the nervous system (eg, Parkinson's disease or multiple sclerosis), other cancer (within the last } 5 \text { yr), depression, } \\
\text { arthritis (select all that apply). }\end{array}$} \\
\hline
\end{tabular}


inclusion included palliative care, insomnia, and body mass index or weight gain or loss, among others. Following prioritization, outcome domains were categorized into three types: survival and disease control; degree of health; and treatment complications.

\subsection{Survival and disease control}

Because prostate cancer is a terminal illness, overall survival and prostate cancer-specific survival were easily prioritized for inclusion in the set. The group recommended that these should be collected via national death indices to improve international comparability. Cancer control, including metastasis-free survival and the development of castration-resistant disease, was also prioritized as essential because of its effect on patient prognosis. In addition, complications from local disease progression and SSE occurrence were prioritized for tracking as they are particularly burdensome to patients. Where possible, we recommend continuous documenting of these disease progression outcomes in structured forms throughout the course of follow-up. Alternatively, annual chart abstraction may be used.

\subsection{Acute treatment complications}

Although acute treatment complications received high prioritization, there was considerable debate as to whether their collection is feasible. Accurate comparability of complication rates across institutions requires reliability of data capture and use of common definitions, which may require time-consuming audits for verification. We recommend an adapted version of the US National Cancer Institute Common Terminology Criteria for Adverse Events version 4 for tracking complication rates [14]. The adapted version simplifies data collection by identifying only grade 3 or 4 complications and assigning a general category (cytopenias, infections, gastrointestinal toxicity, neuropathy, cardiovascular events, or other). We recommend assessment of complications occurring within 6 mo of treatment initiation.

\subsection{PROMS}

HR-QOL is of utmost importance for men with advanced prostate cancer. Because evidence suggests that physicians often inaccurately estimate patient HR-QOL, PROMs have been increasingly used to accurately describe a patient's own perceived result of care [15]. The working group sought to identify a single, practical, validated PROM to capture outcomes important to men with advanced prostate cancer, but no single instrument adequately covered all the prioritized domains (Supplementary material, Appendix 6). Therefore, the working group decided to include both a prostate cancer-specific questionnaire and an overall $\mathrm{QOL}$ questionnaire. Although the group also wanted to include measures of the quality of death and end-of-life care, no well-validated PROMs currently exists for these domains, and we advocate further research to develop a satisfactory tool [16].
The group recognized that it is important to assess prostate cancer-specific $\mathrm{QOL}$ and complications from previous local or hormonal therapy, and considered several instruments according to their representation of questions regarding sexual dysfunction and urinary, bowel, and hormonal symptoms (Supplementary material, Appendix 6). Patient representatives strongly stated that monitoring of these outcomes is important, even among men with advanced disease. We included the Expanded Prostate Cancer Index Composite (EPIC) to assess these complications among men previously treated with local therapy or hormonal therapy because it is a single instrument that assesses the domains of sexual, urinary, hormonal, and bowel function [17]. In addition, it was recommended in the ICHOM localized prostate cancer standard set, allowing a natural continuation of outcome measurement and instrument familiarity for patients who experience recurrence after localized disease [7]. We recommend use of the 26-item form of the EPIC because of its accumulated psychometric evidence. However, we recognize that many institutions will favor the shorter EPIC for clinical practice (EPIC-CP), and consider it a valid alternative, albeit with less accumulated evidence [18]. To improve the interpretability of the sexual function domain of the EPIC, three additional questions regarding libido and the use of sexual medications or devices are also recommended (Table 2).

To measure overall QOL, we evaluated both general tools, including EQ-5D and SF-12, and cancer-specific tools, including FACT-G and European Organization for Research and Treatment of Cancer (EORTC) QLQ-C30 (Supplementary material, Appendix 6). General tools failed to adequately cover the prioritized domains and had less evidence specifically describing use in the population with advanced prostate cancer. Thus, these tools were eliminated. Of the cancer-specific tools, we selected the EORTC QLQ-C30 instrument (Table 2) for several reasons [19]. First, there is validation evidence for patients with advanced prostate cancer. Second, there are many available validated translations that allow easy use internationally. Finally, there is continued investment in the tool to improve its usability over time. Efforts are ongoing to develop a computer adaptive version of EORTC QLQ-C30, which will provide similar domain coverage with higher sensitivity and lower respondent burden [20].

We recommend evaluation of patient-reported health status at the time of enrollment into the advanced prostate cancer standardized set, at least 6 mo after initiation of treatment, and annually until death (Fig. 1). Institutions should ideally strive to measure PROMs as regularly as is feasible to improve patient-provider communication and real-time feedback on health status, although the group recognizes that logistic challenges and potential respondent burden will need to be balanced to make this successful.

\subsection{Baseline characteristics}

In a process similar to that described for outcome domains, the working group developed a prioritized list of factors to collect for adjustment of case mix (Table 3). Following 
Example 1: Patient diagnosed with advanced disease*, receives treatment after diagnosis
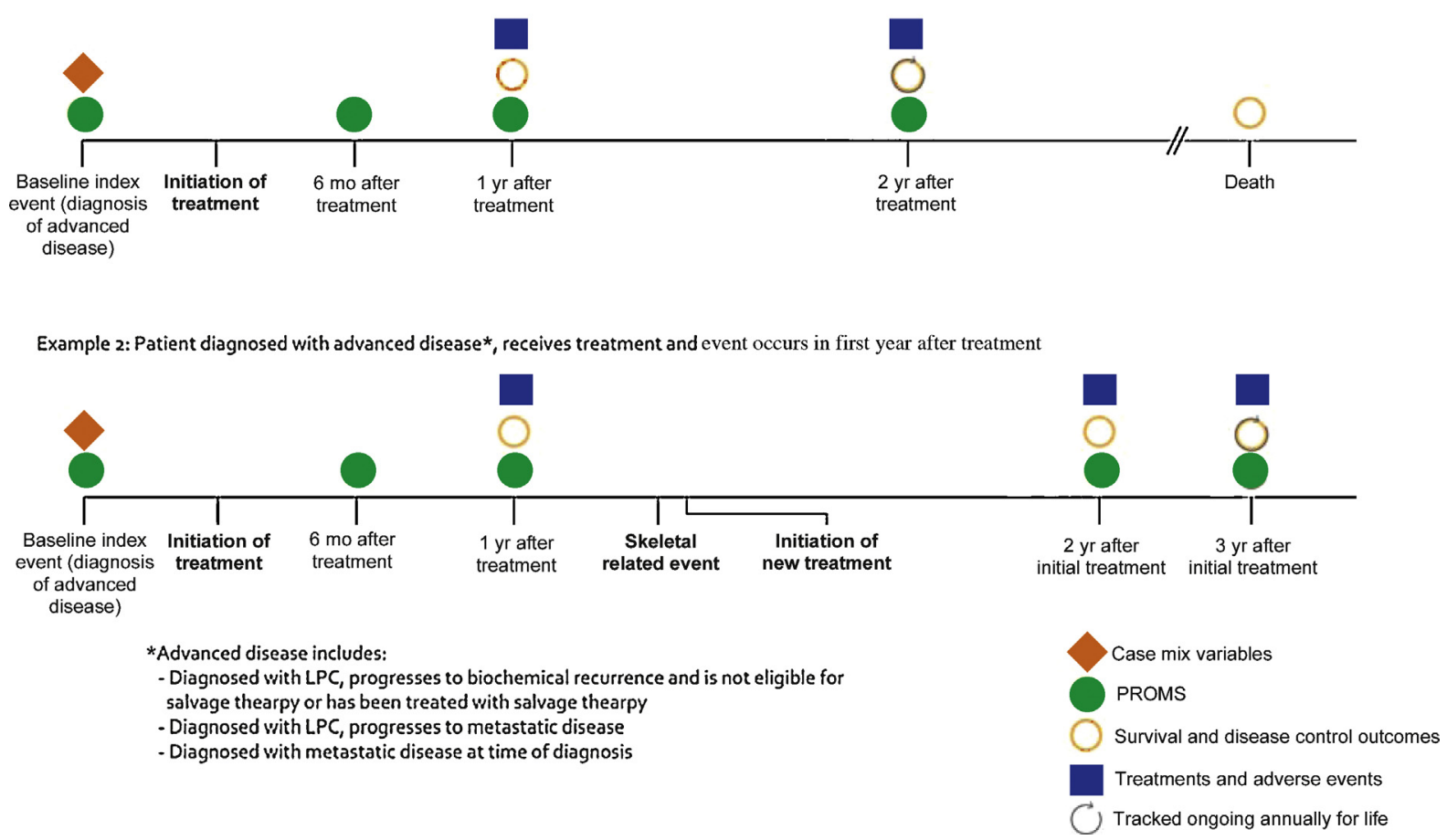

Fig. 1 - Selected sample timelines illustrating when particular outcomes and baseline factors should be collected for patients treated with different modalities. Example 1, one treatment given. Example 2, multiple treatments needed after specific events or disease progression. These timelines are intended to represent the outcome data collection points for possible treatment paths a patient could take, and do not advocate a particular treatment approach. Of note, a majority of baseline factors should be collected at the time of initiation of the advanced prostate cancer set, although several (eg, Gleason score, pathologic stage) are collected from information or treatment at the time of diagnosis. LPC $=$ localized prostate cancer; PROMs = patient-reported outcome measurements.

prioritization, case mix domains were categorized as demographic factors, clinical factors, tumor factors, and previous treatments.

\subsubsection{Demographics}

The decision to include age as a factor that influences patient outcomes was unanimous. Socioeconomic status (SES) is also a key determinant of health outcomes in oncology populations [21,22]. SES can be a difficult factor to quantify for many reasons, including patient unwillingness to share sensitive financial information and the lack of a single measure that accurately reflects its complexity [22]. The working group recommended assessment of SES in terms of the highest level of education attained according to the International Standard of Schooling Classification in each participating country [23]. This measure is one that patients generally feel comfortable reporting, and it can be compared across countries [22]. Evidence suggests that support outside the health care system, including marital status, plays a significant role in prostate cancer outcomes [24]. The working group recommended inclusion of both marital status and living status (eg, I live with partner/ spouse/family/friends or I live alone).

\subsubsection{Clinical factors}

A patient's baseline health status, including pain and the burden of comorbid illness, is a key determinant of survival outcomes and QOL in the oncology population [25]. We recommend the collection of Eastern Cooperative Oncology Group/World Health Organization performance status, comorbidities, hemoglobin levels, pain scores and medication use, and family history of prostate cancer. The choice of a comorbidity assessment tool was particularly challenging because many exist but there is no gold standard. The working group finally endorsed use of the modified selfadministered comorbidity questionnaire (SCQ) to collect data for a list of comorbid diseases [26]. The SCQ predicts functional outcomes as well as the medical record-based Charlson comorbidity index does, and better predicts QOL [27]. The SCQ can also be collected directly from patients, thus avoiding the international inconsistency of administratively coded data.

\subsubsection{Tumor factors}

Disease control and HR-QOL among men with prostate cancer are highly dependent on tumor factors [21]. Clinical (and pathologic where available) tumor grade and stage were naturally included. Prostate-specific antigen level, extent of metastatic disease, and Gleason scores at initial diagnosis were added for adequate risk stratification (Table 3).

\subsubsection{Treatment factors}

Since most patients with advanced prostate cancer have received treatments in the past, the working group decided to include to include treatments given, such as radical prostatectomy, radiation, androgen deprivation therapy 
Table 3 - Summary of outcomes for the International Consortium for Health Outcomes Measurement advanced prostate cancer standard set

\begin{tabular}{|c|c|c|c|c|c|}
\hline Outcome category & Population & Measure & Supporting information & Timing & Data source $^{a}$ \\
\hline ATCs & Patients with ST & $\begin{array}{l}\text { Major ST } \\
\text { complications }\end{array}$ & $\begin{array}{l}\text { Presence/absence of grade } \geq 3 \\
\text { including name of } \\
\text { adverse event while on therapy } \\
\text { and within } 6 \text { mo after TI }\end{array}$ & Update at least annually & Clinical \\
\hline \multirow[t]{10}{*}{$\begin{array}{l}\text { Degree of } \\
\text { health }\end{array}$} & All patients & Performance status & $\begin{array}{l}\text { ECOG/WHO scale for } \\
\text { performance status }\end{array}$ & $\begin{array}{l}\text { Baseline; } 3,6 \text {, and } 12 \text { mo after TI; } \\
\text { ongoing annual tracking for life }\end{array}$ & Clinical \\
\hline & All patients & $\begin{array}{l}\text { Need for pain } \\
\text { medication }\end{array}$ & $\begin{array}{l}\text { Use of OTC pain medicine or } \\
\text { strong pain medicine }\end{array}$ & $\begin{array}{l}\text { Baseline; } 3,6 \text {, and } 12 \mathrm{mo} \text { after TI; } \\
\text { ongoing annual tracking for life }\end{array}$ & PR \\
\hline & All patients & Pain & Tracked via EORTC QLQ-C30 & $\begin{array}{l}\text { Baseline; } 3,6 \text {, and } 12 \mathrm{mo} \text { after TI; } \\
\text { ongoing annual tracking for life }\end{array}$ & PR \\
\hline & All patients & Fatigue & Tracked via EORTC QLQ-C30 & $\begin{array}{l}\text { Baseline; } 3,6 \text {, and } 12 \mathrm{mo} \text { after TI; } \\
\text { ongoing annual tracking for life }\end{array}$ & PR \\
\hline & All patients & Physical functioning & Tracked via EORTC QLQ-C30 & $\begin{array}{l}\text { Baseline; } 3,6 \text {, and } 12 \mathrm{mo} \text { after TI; } \\
\text { ongoing annual tracking for life }\end{array}$ & PR \\
\hline & All patients & $\begin{array}{l}\text { Emotional } \\
\text { functioning }\end{array}$ & Tracked via EORTC QLQ-C30 & $\begin{array}{l}\text { Baseline; } 3,6 \text {, and } 12 \text { mo after TI; } \\
\text { ongoing annual tracking for life }\end{array}$ & PR \\
\hline & All patients & Urinary symptoms & Tracked via EPIC-26 & $\begin{array}{l}\text { Baseline; } 3,6 \text {, and } 12 \mathrm{mo} \text { after TI; } \\
\text { ongoing annual tracking for life }\end{array}$ & PR \\
\hline & All patients & Bowel symptoms & Tracked via EPIC-26 & $\begin{array}{l}\text { Baseline; } 3,6 \text {, and } 12 \mathrm{mo} \text { after TI; } \\
\text { ongoing annual tracking for life }\end{array}$ & PR \\
\hline & All patients & Hormonal symptoms & Tracked via EPIC-26 & $\begin{array}{l}\text { Baseline; } 3,6 \text {, and } 12 \mathrm{mo} \text { after TI; } \\
\text { ongoing annual tracking for life }\end{array}$ & PR \\
\hline & All patients & Sexual dysfunction & $\begin{array}{l}\text { Tracked via EPIC- } 26 \text { and } \\
\text { additional questions }{ }^{b}\end{array}$ & $\begin{array}{l}\text { Baseline; } 3,6 \text {, and } 12 \mathrm{mo} \text { after TI; } \\
\text { ongoing annual tracking for life }\end{array}$ & PR \\
\hline \multirow[t]{6}{*}{$\begin{array}{l}\text { Survival and } \\
\text { disease control }\end{array}$} & All patients & $\begin{array}{l}\text { Procedures } \\
\text { needed for LP }\end{array}$ & $\begin{array}{l}\text { Receipt of specific procedures } \\
\text { because of LP }{ }^{c}\end{array}$ & $\begin{array}{l}1 \mathrm{yr} \text { after TI; ongoing annual } \\
\text { tracking for life }\end{array}$ & Clinical \\
\hline & All patients & $\begin{array}{l}\text { Symptomatic } \\
\text { skeletal event }\end{array}$ & $\begin{array}{l}\text { Symptomatic fracture, cord } \\
\text { compression, or need } \\
\text { for bone surgery or radiation }\end{array}$ & $\begin{array}{l}1 \mathrm{yr} \text { after TI; ongoing annual } \\
\text { tracking for life }\end{array}$ & Clinical \\
\hline & $\begin{array}{l}\text { Patients without } \\
\text { known metastasis }\end{array}$ & $\begin{array}{l}\text { Development of } \\
\text { metastasis }\end{array}$ & $\begin{array}{l}\text { Diagnosed with metastatic } \\
\text { disease }\end{array}$ & $\begin{array}{l}1 \mathrm{yr} \text { after } \mathrm{TI} \text {; ongoing annual } \\
\text { tracking for life }\end{array}$ & Clinical \\
\hline & $\begin{array}{l}\text { Patients who do } \\
\text { not yet have CRD }\end{array}$ & Development of CRD & Diagnosed with CRD ${ }^{d}$ & $\begin{array}{l}1 \mathrm{yr} \text { after TI; ongoing annual } \\
\text { tracking for life }\end{array}$ & Clinical \\
\hline & All patients & $\begin{array}{l}\text { Cause-specific } \\
\text { survival }\end{array}$ & $\begin{array}{l}\text { Was death attributed to } \\
\text { prostate cancer on death } \\
\text { certificate }\end{array}$ & $\begin{array}{l}1 \mathrm{yr} \text { after TI; ongoing annual } \\
\text { tracking for life }\end{array}$ & $\begin{array}{l}\text { Administrative } \\
\text { data (death registry) }\end{array}$ \\
\hline & All patients & Overall survival & Date of death & $\begin{array}{l}1 \mathrm{yr} \text { after TI; ongoing annual } \\
\text { tracking for life }\end{array}$ & $\begin{array}{l}\text { Administrative } \\
\text { data (death registry) }\end{array}$ \\
\hline \multicolumn{6}{|c|}{$\begin{array}{l}\text { ATCs = acute treatment complications; ST = systemic therapy; TI = treatment initiation; ECOG = Eastern Cooperative Oncology Group; WHO = World Health } \\
\text { Organization; PR = patient-reported; OTC = over the counter; EORTC = European Organization for Research and Treatment of Cancer; EPIC = Expanded Prostate } \\
\text { Cancer Index Composite; LP = local progression; CRD = castration-resistant disease. } \\
\text { a The data source reflects the way in which case mix variables and outcomes are collected. Clinical data include data abstraction and physician reports. PR } \\
\text { data include PR outcome measures (eg, EORTC QLQ-C30, EPIC-26) and other relevant PR questions. } \\
\text { b During the last } 4 \text { wks, to what extent were you interested in sex?: not at all, a little, quite a bit, very much; (2) Have you used any medications or devices to } \\
\text { aid or improve erections?: yes/no; and (3) For each of the following medications and devices, please indicate whether or not you have tried or currently use } \\
\text { it to improve your erections: Viagra or other pill, Muse (intraurethral alprostadil suppository), penile injection therapy (such as Caverject), vacuum erection } \\
\text { device (such as Erect-Aid), other (have not tried it; tried it, but was not helpful; it helped, but I am not using it now; it helped and I use it sometimes; it } \\
\text { helped and I use it always). } \\
\text { c Procedures include transurethral resection of the prostate, ureteral stent, percutaneous nephrostomy tube, suprapubic catheter placement, chronic Foley } \\
\text { catheter, and intermittent self-catheterization. } \\
\text { d Defined as two successive increases in prostate-specific antigen at least } 1 \mathrm{wk} \text { apart or the development or progression of radiographically proven } \\
\text { metastatic lesions in the setting of castrate levels of testosterone }(<50 \mathrm{ng} / \mathrm{ml}) \text {. }\end{array}$} \\
\hline
\end{tabular}

(ADT), prior systemic treatments other than ADT, and antiresorptive agents (Table 3 ).

\subsection{Data collection}

One of the ultimate goals of the ICHOM efforts is to provide a single set of standard data that can be compared across health care systems, countries, and patient populations. A reference guide including sample questionnaires and a data dictionary designed for each standard set created by the ICHOM is an integral part of implementing the measurement process, and will facilitate standardization of data collection. The guide is free and is available on the
ICHOM website (www.ichom.org/medical-conditions/ advanced-prostate-cancer).

\section{Discussion}

Transparent measurement of outcomes and costs has the potential to align patients, providers, and payers towards a common goal of improving the value of care for patients with advanced prostate cancer. Accurate assessments of value require comparison of the same outcomes with the same measures in a way that accounts for variability in baseline health and prior therapies. Our working group, deliberately comprising a diverse array of experts, reviewed 
existing measures to define a standard set of outcomes we felt mattered most to patients with advanced prostate cancer, along with corresponding case mix factors. We believe that the standardized measurement and reporting of these outcomes from routine clinical care can lead to accurate assessments of health care quality and practice patterns in real-life populations, and could ultimately accelerate the adoption of best practices.

The working group acknowledges that collection of this standard set requires significant upfront investment in information technology and/or data collection resources. Organizations will certainly vary in their readiness to adopt the set. Our intent is to facilitate adoption in a piecemeal fashion, beginning with pilot institutions from the working group. We anticipate significant learning from this early testing phase that will allow the set to be refined as it is rolled out further. To steer this refinement, a steering committee of experts comprising balanced representation from the working group will convene annually to consider changes in the set over time.

The working group recognizes that inclusion of two PROM questionnaires comprising more than 50 questions represents a significant respondent burden. Ultimately, we felt that the trade-off in domain coverage outweighed the number of questions. A similar respondent burden has been successfully managed for other conditions as long as the questions answered remain salient for the patient [28]. In time, we anticipate a lower respondent burden with the transition to computer adaptive tests covering these same domains.

Our process and recommendations have some limitations that should be considered. First, although the recommendations reflect a systematic assessment of the literature and informed consensus among an international team of experts, the suggested outcomes and measures remain expert opinion. Other group efforts, such as PROQOLID, serve a separate purpose in compiling PROM instrument information to allow easy identification of an instrument that measures the information of interest in a given population, but does not incorporate expert opinion into the process [29]. We sought to both identify outcomes of interest and provide expert opinion to expedite largescale implementation as swiftly as possible. Second, new PROMs may be developed that were not considered in our review. The steering committee will review these developments annually and recommend whether to transition to a new instrument for the same domain. Third, the standard set recommended has not yet been proven in routine use. For greater confidence in its usefulness and usability in routine clinical practice, pilot testing will be needed.

Despite these concerns, we recommend this set as a starting point towards routine collection of patientcentered outcomes for men with advanced prostate cancer.

\section{Conclusions}

The advanced prostate cancer standard set was developed by an international, multidisciplinary team to standardize the measurement of outcomes deemed most important to men with advanced prostate cancer. The working group recommends measurement of these outcomes in routine clinical practice to permit accurate assessments and comparison of the value of care and to facilitate improvement initiatives worldwide.

Author contributions: Alicia K. Morgans had full access to all the data in the study and takes responsibility for the integrity of the data and the accuracy of the data analysis.

Study concept and design: Stowell.

Acquisition of data: All authors.

Analysis and interpretation of data: All authors.

Drafting of the manuscript: Morgans, van Bommel, Stowell.

Critical revision of the manuscript for important intellectual content: All authors.

Statistical analysis: None.

Obtaining funding: Stowell.

Administrative, technical, or material support: van Bommel.

Supervision: Penson, Stowell.

Other: None.

Financial disclosures: Alicia K. Morgans certifies that all conflicts of interest, including specific financial interests and relationships and affiliations relevant to the subject matter or materials discussed in the manuscript (eg, employment/affiliation, grants or funding, consultancies, honoraria, stock ownership or options, expert testimony, royalties, or patents filed, received, or pending), are the following: None.

Funding/Support and role of the sponsor: This work was funded by the Movember Foundation. The sponsor played a role in manuscript review.

\section{Appendix A. Supplementary data}

Supplementary data associated with this article can be found, in the online version, at http://dx.doi.org/10.1016/j. eururo.2015.06.007.

\section{References}

[1] Cancer Research UK. Prostate cancer statistics, September 2014. http://publications.cancerresearchuk.org/downloads/Product/ CS_KF_PROSTATE.pdf

[2] National Comprehensive Cancer Network. Clinical practice guidelines in oncology: prostate cancer, v.2.2014. www.nccn.org/ professionals/physician_gls/pdf/prostate.pdf

[3] Cookson MS, Roth BJ, Dahn P, et al. Castration-resistant prostate cancer: AUA guideline; 2014, www.auanet.org/common/pdf/ education/clinical-guidance/Castration-Resistant-Prostate-Cancer. pdf

[4] Heidenreich A, Bastian PJ, Bellmunt J, et al. EAU guidelines on prostate cancer. Part II: treatment of advanced, relapsing, and castration-resistant prostate cancer. Eur Urol 2014;65:467-79.

[5] Fisher ES, Wennberg DE, Stukel TA, et al. The implications of regional variations in Medicare spending. Part 1: the content, quality, and accessibility of care. Ann Intern Med 2003;138:273-87.

[6] Porter ME. What is value in health care? N Engl J Med 2010; 363:2477-81.

[7] Martin NE, Massey L, Stowell C, et al. Defining a standard set of patient-centered outcomes for men with localized prostate cancer. Eur Urol 2015;67:460-7.

[8] Macefield RC, Jacobs M, Korfage IJ, et al. Developing core outcomes sets: methods for identifying and including patient-reported outcomes (PROs). Trials 2014;15:49. 
[9] Efficace F, Bottomley A, Osoba D, et al. Beyond the development of health-related quality-of-life (HRQOL) measures: a checklist for evaluating HRQOL outcomes in cancer clinical trials-does HRQOL evaluation in prostate cancer research inform clinical decision making? J Clin Oncol 2003;21:3502-11.

[10] Efficace F, Bottomley A, van Andel G. Health related quality of life in prostate carcinoma patients: a systematic review of randomized controlled trials. Cancer 2003;97:377-88.

[11] American Joint Committee on Cancer. Prostate. In: Edge SB, Byrd DR, Compton CC, et al., editors.AJCC Cancer Staging Manual. ed. 7. New York, NY: Springer; 2010. p. 457-68.

[12] Cookson MS, Aus G, Burnett AL, et al. Variation in the definition of biochemical recurrence in patients treated for localized prostate cancer: the American Urological Association Prostate Guidelines for Localized Prostate Cancer Update Panel report and recommendations for a standard in the reporting of surgical outcomes. J Urol 2007; $177: 540$.

[13] Roach 3rd M, Hanks G, Thames Jr H, et al. Defining biochemical failure following radiotherapy with or without hormonal therapy in men with clinically localized prostate cancer: recommendations of the RTOG-ASTRO Phoenix Consensus Conference. Int J Radiat Oncol Biol Phys 2006;65:965.

[14] US Department of Health and Human Services. Common terminology criteria for adverse events (CTCAE) version 4.0. http://evs.nci.nih. gov/ftp1/CTCAE/CTCAE_4.03_2010-06-14_QuickReference_5x7.pdf

[15] Sanda MG, Dunn RL, Michalski J, et al. Quality of life and satisfaction with outcome among prostate-cancer survivors. N Engl J Med 2008;358:1250-61.

[16] Curtis JR, Downey L, Engelberg RA. The quality of dying and death: is it ready for use as an outcome measure? Chest 2013;143:289-91.

[17] Wei JT, Dunn RL, Litwin MS, Sandler HM, Sanda MG. Development and validation of the expanded prostate cancer index composite (EPIC) for comprehensive assessment of health-related quality of life in men with prostate cancer. Urology 2000;56:899-905.

[18] Chang P, Szymanski KM, Dunn RL, et al. Expanded prostate cancer index composite for clinical practice: development and validation of a practical health related quality of life instrument for use in the routine clinical care of patients with prostate cancer. J Urol 2011;186:865-72.

[19] Aaronson NK, Ahmedzai S, Bergman B, et al. The European Organization for Research and Treatment of Cancer QLQ-C30: a quality-oflife instrument for use in international clinical trials in oncology. J Natl Cancer Inst 1993;85:365-76.

[20] Petersen MA, Groenvold M, Aaronson NK, et al. Development of computerised adaptive testing (CAT) for the EORTC QLQ-C30 dimensions-general approach and initial results for physical functioning. Eur J Cancer 2010;46:1352-8.

[21] Aarts MJ, Koldewijn EL, Poortman PM, et al. The impact of socioeconomic status on prostate cancer treatment and survival in the southern Netherlands. Urology 2013;81:593-9.

[22] Shavers VL. Measurement of socioeconomic status is health disparities research. JAMA 2007;99:1013-23.

[23] United Nations Educational, Scientific and Cultural Organization. International standard classification of education: ISCED 2011. www.uis.unesco.org/Education/Documents/isced-2011-en.pdf

[24] Tyson MD, Andrews PE, Etzioni DA, et al. Marital status and prostate cancer outcomes. Can J Urol 2013;20:6702-6.

[25] Armstrong AJ, Garrett-Mayer E, Ou Yang YC, et al. Prostate-specific antigen and pain surrogacy analysis in metastatic hormonerefractory prostate cancer. J Clin Oncol 2007;25:3965-70.

[26] Sangha O, Stucki G, Liang MH, Fossel AH, Katz JN. The selfadministered comorbidity questionnaire: a new method to assess comorbidity for clinical and health services research. Arthritis Rheum 2003;49:156-63.

[27] Olomu AB, Corser WD, Stommel M, et al. Do self-report and medical record comorbidity data predict longitudinal functional capacity and quality of life health outcomes similarly? BMC Health Serv Res 2012;12:398.

[28] Browne J. Response rates to the BREAST-Q are high in a routine practice setting. Plast Reconstr Surg 2012;130, 481e-2e.

[29] PROQOLID. Mapi Research Trust, 2001-2016. http://proqolid.org 